\title{
A Simulation Study on the Temperature Response of W/Cu Divertor Monoblocks under High Heat Fluxes
}

Chun $\mathrm{LI}^{1,2,{ }^{*}, \text { Si-Xiang ZHAO }}{ }^{3}$, Shi-Yu MA ${ }^{1}$, Wei LIU ${ }^{2}$ and Yuan-Zhi ZHU ${ }^{1}$

${ }^{1}$ College of Mechanical and Materials Engineering, North China University of Technology, Beijing, 100144, China

${ }^{2}$ School of Materials Science and Engineering, Tsinghua University, Beijing, 100084, China

${ }^{3}$ Institute of Modern Physics, Chinese Academy of Sciences, Lanzhou,730000, China

*lichun@ncut.edu.cn

Keywords: Nuclear material, W/Cu divertor monoblock, Temperature, High heat flux.

\begin{abstract}
High heat removal efficiency is an important requirement for the W/Cu divertor monoblocks in the design of future fusion reactors. In this study the stationary surface temperature distribution and the effects of armour thickness and coolant flow velocity on the thermal behavior of $\mathrm{W} / \mathrm{Cu}$ monoblocks under high heat flux (HHF) loading has been investigated with steady finite element analysis. During HHF loading, a swath of low-temperature area with two extended parts was observed on the model surface, which is mainly related to the Gaussian distribution of heat fluxes and the heat dissipation from ending tubes. The stationary surface temperature showed a linear increasing function of armour thickness and a power decreasing function of flow velocity. It is thus concluded that the way to reduce the surface temperature of a monoblock by raising coolant flow velocity has an upper limit while the way by reducing armour thickness is effective continuously, especially under a higher heat flux.
\end{abstract}

\section{Introduction}

Magnetic confinement Tokamaks are the most promising of several proposed nuclear fusion devices. Divertors are the important components of Tokamaks to control impurity, export heat flow and exhaust helium dust [1,2]. Tungsten (W) is considered as a promising candidate divertor armor material for future use in Tokamaks, such as ITER and the upgraded EAST, due to its high melting point, high thermal conductivity, low tritium inventory and other favorable characteristics $[3,4]$. In the design of a full $\mathrm{W}$ divertor, $\mathrm{W} / \mathrm{Cu}$ monoblock components are used in the vertical targets, to avoid falling down of the debonded armor tiles, as well as to reduce the electromagnetism and thermal stress $[2,5]$. Because the vertical targets are subject to the most intense stationary heat loads, high heat removal efficiency is a key requirement for the monoblock components $[2,4]$.

Based on heat transfer and hydrodynamics, smaller armor thickness and higher coolant flow velocity are favorable for reducing the surface temperature. But larger armor thickness is advantageous in terms of the erosion lifetime and lower flow velocity means lower energy consumption and lower cost. Therefore, it will have reference significance for the engineering design of divertor components to investigate the surface temperature distribution and the effects of armour thickness and coolant flow velocity on the thermal behavior of $\mathrm{W} / \mathrm{Cu}$ monoblocks under high heat flux (HHF) loading.

\section{Methods}

In this study, the ANSYS-FLUENT code was used for the steady finite element analysis (FEA) [6]. Fluid-solid conjugated heat transfer of three-dimensional (3D) coupled models were simulated to investigate the mock-up thermal behavior and the effects of armor thickness and coolant flow velocity. The material properties parameters referred to ITER internal material database file. 
During modeling, a kind of ITER-like W/Cu monoblock mock-ups used in HHF tests were taken as the reference, which were produced by ASIPP and AT\&M company, China. Figs. 1a and 1b respectively show the schematic cross-section and the appearance of these mock-ups with $4 \mathrm{~mm}$ thickness armor. It was composed of $5 \mathrm{~W}$-tiles $(12 \times 24 \times 28 \mathrm{~mm} 3)$. Oxygen-free $\mathrm{Cu}(\mathrm{OFC})$ interlayer thickness is $1 \mathrm{~mm}, \mathrm{CuCrZr}$ coolant tube OD/ID is $15 \mathrm{~mm} / 12 \mathrm{~mm}$, and ending tube length of $80 \mathrm{~mm}$ (including $50 \mathrm{~mm}$ coolant tube). The geometry model used in simulations are shown in Fig. 1c.
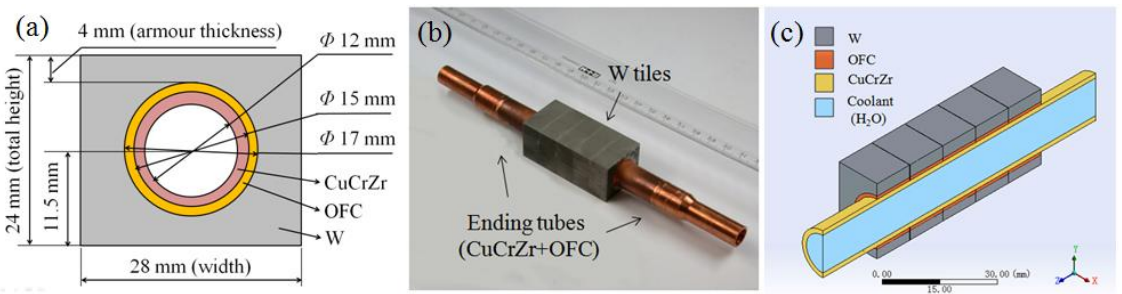

Fig. 1. The ITER-like W/Cu monoblock mock-up.(a) Schematic diagram, (b) Appearance, (c) 3D finite element model.

\section{Results and Discussion}

\section{The Stationary Surface Temperature Distribution}

In order to evaluate the thermal fatigue property of divertor components, researchers commonly use energy beams generating constant or Gaussian fitted HHF to simulate uniform or actual fusion heat loading respectively [2]. The Gaussian fitted heat flux parameters used in this study simulated the heat flux generated in the neutral beam HHF test facility GLADIS [7] at IPP Garching, Germany. In this paper, the core power density is used to describe the Gaussian fitted HHF loading.

Fig. $2 \mathrm{a}$ and $2 \mathrm{~b}$ respectively show the calculated temperature distributions of a $10 \mathrm{MW} / \mathrm{m} 2$ Gaussian fitted and constant HHF. They show the characteristics of surface temperature distribution: a swath of low-temperature area existed along the coolant tube with two extended parts, one big and one small, respectively at the inlet- and outlet-side, especially under Gaussian fitted HHF; meanwhile, slight temperature increase was observed on the near W-tile parts of the ending tubes.

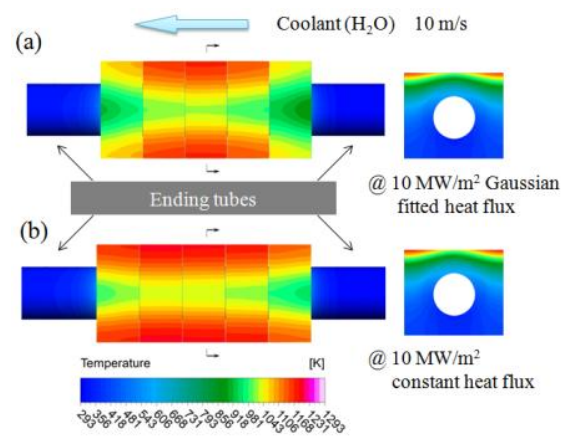

Fig. 2. The top view and cross-section temperature contour plots obtained from simulations with different HHFs.

Ref. [8] reported the surface temperature distribution of $\mathrm{Cu}$-PFU samples with $\mathrm{W}$ coating in Gaussian fitted HHF tests, which was similar to Fig. 2a. The authors attributed this to the lower heat flux loaded on ends than that on center. However, slight temperature increase on the ending tubes indicates the heat capacity and thermal conductance of the ending tubes may play a role, although no HHF acted directly on them. So, 3D geometry models without ending tubes were also considered in our study. The results are shown in Fig. 3.

The low-temperature area with similar characteristics can be seen in Fig. 3a, but smaller than that in Fig. 2a. And in the case of constant HHF( Fig. 3b), the extended low-temperature part even disappeared at the outlet-side 
Above comparative study indicates that both the Gaussian heat flux pattern and the heat dissipation through ending tubes. lead to the temperature decrease at the two ends of mock-ups, forming the extended part of low-temperature area at the outlet-side, as well as the relatively larger low-temperature area at the inlet-side.

(a)

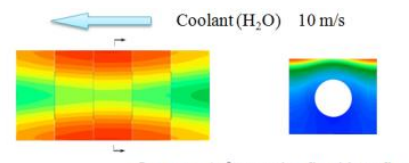

(b)

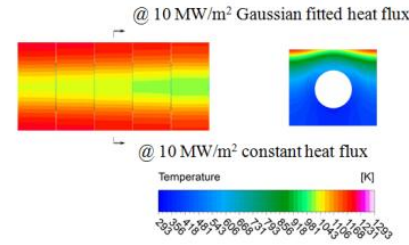

Fig. 3. The top view and cross-section temperature contour plots obtained from simulations with different HHFs acting on the model without ending tubes.

\section{The Effects of Armor Thickness and Coolant Flow Velocity}

Figs. $4 \mathrm{a}$ and $4 \mathrm{~b}$ respectively shows the surface temperature variation with armor thickness and coolant flow velocity. A linear relationship between temperature and armor thickness can be found in Fig. 4a. The slope increases with the increase of loading power density, reflecting the influence of armor thickness was more remarkable under higher power density loading. And as seen in Fig. $4 \mathrm{~b}$, the surface temperature decreases with the increasing flow velocity and attained a final stable status, showing that the cooling effect of a certain coolant has an upper limit for a given monoblock structure.
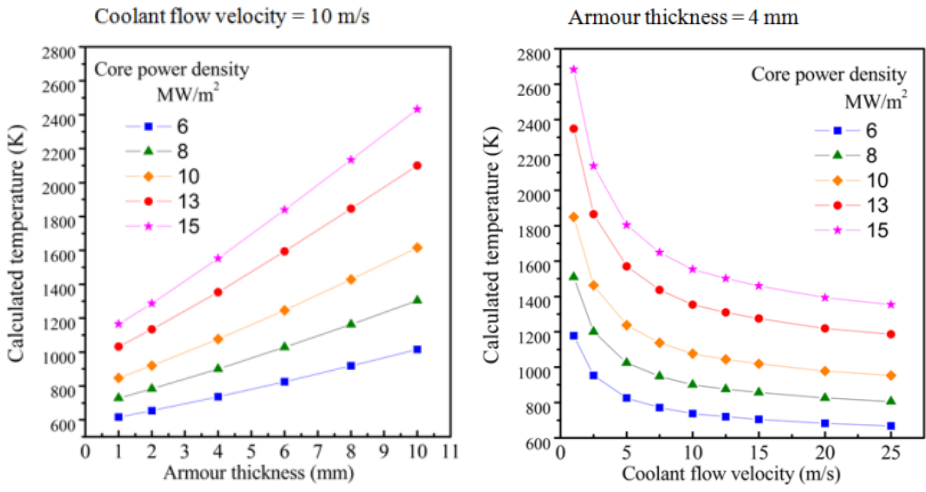

Fig. 4. The calculated surface temperature variation with armor thickness (a) and coolant flow velocity (b).

The above results are discussed based on heat transfer theory [9]. Without considering thermal radiation, the surface temperature of mock-ups $\mathrm{T}_{\text {surf }}$ can be basically expressed as

$$
T_{\text {surf }}=T_{\text {water }}+\Delta T_{\text {convection }}+\Delta T_{\text {conduction }}
$$

in which, $T_{\text {water }}$ is the temperature of the cooling water; $T_{\text {convection }}$ is the convective term; $T_{\text {conduction }}$ is the conductive term, composed by the temperature differences in the $\mathrm{W}$-tile, the $\mathrm{Cu}$ tube, and the $\mathrm{CuCrZr}$ tube, respectively expressed as $T_{\mathrm{w}} T_{\mathrm{cu}} T_{\text {cucrzr }}$ The armor thickness. mainly affects $T_{\mathrm{w}}$. If the $\mathrm{W}$-tile is simplified into a block model, there is

$$
T_{\text {surf }}=T_{\text {water }}+\Delta T_{\text {convection }}+\Delta T_{\text {cucrar }}+\Delta T_{\text {cu }}+\left(P / \lambda_{\mathrm{w}}\right) \delta
$$


in which, $P$ is the input power density; ${ }_{w}$ is the thermal conductivity of $\mathrm{W}$. Thus, there is only one first-order term related to armor thickness, resulting in a linear relationship. The slope is related to the reciprocal of $\mathrm{W}$ thermal conductivity, which increases with the increase of temperature. In the case of higher input power density, the sample temperature is higher, leading to a higher slope.

On the other hand, the coolant flow velocity $v$ mainly affects the convective term $T_{\text {convection }}$ in Eq. (1) by affecting the coolant flow conditions. This term can be briefly expressed as

$$
\Delta T_{\text {convection }}=P / h
$$

in which, $h$ is the convective heat transfer coefficient. For turbulent forced convection in tubes, according to empirical formulas such as Dittus-Boelter equation and Gnielinski correlation [9], $h$ is related to a power function of Reynolds number $R e$, and the exponent is denoted by $a$. $R e$ reflects the coolant flow condition and is a linear function of $v$. Thus, $T_{\text {surf }}$ can be expressed in a simplified form as

$$
T_{\text {surf }}=P / f\left(v^{a}\right)+T_{\text {water }}+\Delta T_{\text {conduction }}
$$

This shows that the relationship between temperature and flow velocity could be approximately described as a power function.

\section{Conclusions}

The stationary surface temperature distribution of W/Cu monoblocks under HHF loading and its influence factors have been investigated with steady finite element analysis in this study.

A swath of low-temperature area along the coolant tube with two extended parts were observed on the surface temperature contour plots during HHF loading. This phenomenon is mainly related to the Gaussian distribution of heat fluxes and the heat dissipation from ending tubes.

For the heat transfer of monoblocks, armor thickness affects the heat conduction process in Wtiles and coolant flow velocity affects the heat convection by affecting the coolant flow conditions. The stationary surface temperature shows to be a linear increasing function of armour thickness and a power decreasing function of flow velocity, indicating the increase of cooling efficiency by raising coolant flow velocity has an upper limit for a given monoblock structure while by reducing armor thickness, i.e. optimizing the structure material and design, will have greater potential, especially under higher heat fluxes.

\section{Acknowledgement}

This work is supported by National Magnetic Confinement Fusion Science Program of China under Grant 2013GB109004, 2014GB117000, and research start-up fund of North China University of Technology.

\section{References}

[1] A. Pironti, M. Walker, IEEE Control Systems 25, 30 (2005).

[2] Q. Li, Research on design and manufacturing of PFMC for EAST divertor, PhD thesis, University of Chinese Academy of Sciences, (China, 2012).

[3] Z.B. Zhou, D.M. Yao, L. Cao, et al., IEEE Trans. Plasma Sci.42, 580 (2014).

[4] T. Hirai, F. Escourbiac, S. Carpentier- Chouchana, et al., Phys. Scr.T159,014006 (2014).

[5] S. Suzuki, K. Ezato, Y. Seki, et al.,Fusion Eng. Des.87,845 (2012). 
[6] J.Q. Chen, J.C. Yu, M.L. Liu, The technical foundation and engineering applications of ANSYS FLUENT: Flow heat transfer and environmental pollution control (China Petrochemical Press, Beijing, 2014).

[7] H. Greuner, B. Böswirth, J. Boscary, et al. J. Nucl. Mater.367-370, 1444 (2007).

[8] M. Richou, M. Missirlian, D. Guilhem, et al.,Fusion Eng. Des.98-99,1394 (2015).

[9] J.G. Collier, J.R. Thome, Convective boiling and condensation (Oxford University Press, New York,1994). 